\title{
The New Suburb: Multiethnic Racial Residential Integration in the United States
}

\author{
Ankit Rastogi \\ University of Wisconsin-Madison \\ arastogi4@wisc.edu
}

Draft: $8 / 5 / 2019$

\begin{abstract}
This article examines the relatively widespread trend toward racial residential integration within suburbs in the $21^{\text {st }}$ century across metropolitan areas in the United States. I investigate the racial and ethnic compositions of stably integrated communities as well as the characteristics that distinguish these places. Using the information theory index $(\mathrm{H})$ among stably diverse places, I identify cities and suburbs that were racially integrated between 2000 and 2010. Integrated places cluster in highly diverse, coastal metropolitan areas and almost entirely within suburbs. Moreover, integration is firmly patterned along racial lines. Reflecting the antiblack nature of segregation in the US, the rate of black-white integration remains remarkably low $(10.5 \%)$, but in multiethnic communities with Asians and Latinxs, the probability of black-white integration nearly quadruples $(40.1 \%)$. Several critical features of place are positively associated with integration: military and public sector employment as well as public university enrollment; new housing stock; and metropolitan political fragmentation. This study shows that suburbs are at the leading edge of American diversification and integration and illuminates the existence of communities where American society transgresses persistent forms of racial discrimination.
\end{abstract}

Keywords: racial integration; suburbs; diversity; race and ethnicity

\section{ACKNOWLEDGMENTS}

I am grateful for feedback from Katherine Curtis, Myra Marx Ferree, Jack DeWaard, Isabel Pike, Christine Schwartz, H. Jacob Carlson, and Pamela Oliver, as well as for support from the Center for Demography and Ecology at the University of Wisconsin-Madison [P2C HD047873], the National Institute on Aging Training Grant [T32 AG000129], and the Horowitz Foundation for Social Policy. I presented earlier versions of this article to the Race and Ethnicity Research Group and the Center for Demography and Ecology's Training Seminar at the University of Wisconsin-Madison. 


\section{The New Suburb: Multiethnic Racial Residential Integration in the United States}

Since the passage of the Fair Housing Act of 1968, overall levels of metropolitan racial residential segregation have declined gradually (Massey 2015). Still, segregation between whites and blacks remains staggeringly high and segregation between Asians and whites and Latinxs and whites remains relatively unchanged (Massey 2015). However, while metropolitan-wide segregation endures, the scholarly focus on metropolitan areas neglects the uneven changes in racial structure within cities and suburbs and the possibility of racial residential integration in more local contexts. In the $21^{\text {st }}$ century, new trends in racial diversification in suburbs, specifically in communities developed after the passage of antidiscrimination legislation, provide new openings for multiethnic, racially integrated communities. Analyzing suburbs separately from cities, rather than collapsed together as metropolitan areas, may offer new insights regarding American race relations with far-reaching implications for racial inequality.

Suburbs now contribute more to American racial and ethnic diversity than ever before (Frey 2018). While postwar suburbanization and white flight in the $20^{\text {th }}$ century constructed suburbs as a white domain (Boustan 2010; Jackson 1987), the majority of people of color now live in suburbs (Frey 2018). For example, in the Atlanta and Washington, DC metro areas, roughly $80 \%$ of black residents live outside the city (Lacy 2016). In addition, immigrants often bypass the central city and settle directly in suburbs (Frey 2018), and the majority of immigrants lived in suburbs as of 2010 (Wilson and Singer 2011). In multiethnic metro areas like New York and Houston, census tracts comprising blacks, Latinxs, Asians, and whites together are almost entirely located in suburbs (Bader and Warkentien 2016; Logan and Zhang 2010). In 2010, 2.6 million Los Angeles area residents lived in a suburb without a racial or ethnic majority, and an additional 1.9 million lived in a white majority suburb that was at least $20 \%$ people of color (author's calculations, Census 2010).

The emergence of local and racial and ethnic diversity in suburbia is a typically underappreciated finding in the literature on residential segregation. Understanding the determinants of stably integrated communities is important for understanding potential future trends as the US grows more diverse, but there is a dearth of research on factors associated with residential integration. Past literature identifies variables, like the size of the local black population or the presence of manufacturing jobs, that predict segregation (Charles 2003; Lichter, Parisi, and Taquino 2015b), residential mobility (Crowder, Pais, and South 2012), and white flight/racial succession in desegregating spaces (Bader and Warkentien 2016; Logan and Zhang 2010). However, these studies do not use complementary factors to explain the persistence of integrated communities, for example, specific racial and ethnic compositions that perpetuate stable integration, new suburbs without a history of redlining, or jobs that are more equally distributed across racial and ethnic groups. Identifying the contexts that support integration remains a key policy issue and an indicator of racial (in)equality, where segregation contributes to racial disparities in wealth (Flippen 2004), employment (Kneebone and Holmes 2015), and education (Logan, Minca, and Adar 2012).

In this article, I address two central questions about racial residential integration in the United States. First, which racial and ethnic groups are more likely to integrate within place? I conceptualize integrated places as those where people of different races and ethnicities live near each other regardless of the precise racial and ethnic composition of the community. Using a 
common measure of residential integration and segregation, the information theory index (Reardon and Firebaugh 2002), I identify racially and ethnically diverse cities and suburbs that display durable integration across the 2000 and 2010 censuses. I then examine how different combinations of blacks, Latinxs, Asians, and whites moderate the probability of integration among these communities. Adopting this approach allows for an analysis of how racial boundaries within the American racial order promote or obstruct residential integration. For example, multiethnic suburbs may show a greater frequency of integration than suburbs comprising only blacks and whites.

Second, this study is the first to analyze the social conditions and ecological characteristics of places that shape the persistence of racially integrated communities. The varying prevalence of racial and ethnic diversity across the metropolitan US suggests that broader social and ecological conditions influence the emergence of integration, for example, economies that may provide middle-class employment to people of color or new housing built after the passage of antidiscrimination legislation. By including a wide range of explanatory variables at the place and metropolitan levels, this analysis constitutes a comprehensive investigation of the contextual features that facilitate residential integration within American cities and suburbs.

I show that, despite ubiquitous metropolitan segregation, residential integration affects millions of people in suburbs and that there are specific social and economic conditions that provide fertile ground for integration. In an era of public racial animus, I illuminate the coexistence of contrary realities where American society transgresses many persistent forms of racial discrimination. Racial residential segregation is fundamental for the inequitable distribution of material resources across groups (Massey and Denton 1993). From a historical Civil Rights perspective, integration is a remedy for this social problem and may provide people of color access to higher quality, place-based resources generally available to metropolitan whites. Moreover, integration may help prepare whites to live and work in an increasingly diverse, democratic society.

\section{Determinants of integration}

Fifty years have passed since the passage of both the Fair Housing Act of 1968 (FHA) and the Immigration and Nationality Act of 1965 (INA). The FHA struck down legal barriers to integration and the INA opened American borders to immigration regardless of national origin. These acts have fundamentally altered the demographic mix of the United States and set the structural conditions for a multiethnic, residentially integrated society among blacks, Latinxs, Asians, and whites (Maly 2005). In 1970, blacks composed 11.1\% of the American population, Latinxs 4.4\%, Asians 0.8\%, and whites 83.5\% (Gibson and Jung 2005). By 2010, Latinx and Asian shares grew dramatically to $16.3 \%$ and $4.9 \%$, while black shares remained relatively stable at $12.6 \%$ and whites declined to $63.7 \%$ (Humes, Jones, and Ramirez 2011).

With this expanding diversity, multiethnic census tracts have emerged and are increasingly prevalent. These tracts demonstrate compositional stability over decades and exist within and around metropolises in all regions of the US (Logan and Zhang 2010). In the most diverse, multiethnic metro areas like San Francisco, Miami and Houston, multiethnic census tracts (i.e., those with substantial black, Latinx, Asian and white populations) host nearly $30 \%$ of blacks and Latinxs (Zhang and Logan 2016). Notably, these tracts do not show evidence of white flight, and while some exhibit gradual racial succession over decades, others display durable integration (Bader and Warkentien 2016). 
While these studies skillfully track the trajectories of racial and ethnic change creating multiethnic spaces, they do not pinpoint the structural conditions of place which facilitate residential integration. The literature identifies two central dimensions along which integration might emerge and persist, namely racial and ethnic composition and the features of place.

\section{The multiethnic underpinnings of integration}

The first dimension, the racial and ethnic composition of place, reflects American race relations and forms the basis for which groups integrate with each other. While black-white integration alone remains rare, multiethnic compositions may stabilize diversity over time. Referred to as "buffering," the presence of other populations of color like Asians and Latinxs appear to facilitate black-white co-residence. Empirically, whites are less likely to leave census tracts when blacks arrive following an established Asian or Latinx presence (Crowder et al. 2012). Communities with all four groups display the lowest levels of segregation compared to other racial and ethnic combinations (Parisi, Lichter, and Taquino 2015).

Multiethnic spaces transform racialized power in ways that stabilize diversity and integration. These compositions may promote racial acceptance while simultaneously requiring whites to behave differently as they lose majority status. In "hyperdiverse" Southeast Seattle, Lumley-Sapanski and Fowler (2017) show that no single racial and ethnic group can monopolize the urban planning process. Instead, residents must form cross-racial coalitions to implement change. In what the authors term "planning dissonance," change is slow with multiple stakeholders, which creates barriers to re-segregation and actively reinforces stable diversity. Nyden et al. (1998) suggest that bi-racial integrated neighborhoods arise through community intention, where residents articulate an active awareness of diversity and community organizations promote this awareness. Conversely, in multiethnic neighborhoods, the lack of numerical, social, and political dominance by any one group allows integration to arise without direct intention by residents or organizations. The authors provide the examples of Edgewater, Chicago and Jackson Heights, Queens - neighborhoods that have been home to multiple racial and ethnic groups including whites since before 1980. The lack of a single dominant group blurs the boundaries between in- and out-group promoting a new sense of community belonging among diverse stakeholders.

Some studies suggest that racial attitudes have changed such that white subpopulations now opt into multiethnic integrated settings. From findings stemming from the gentrification literature, some whites are attracted to the "hip" settings of racially diverse neighborhoods. Rather than remaking these neighborhoods in their own image, these whites embrace diversity and hope to preserve the social structure of these neighborhoods (Brown-Saracino 2009). In greater DC, survey research indicates that whites report high satisfaction, more so than their people-of-color counterparts, in quadrivial neighborhoods - neighborhoods that are at least 10\% black, Latinx, Asian, and white without a majority (Bader 2016). While evidence of "positive" white racial attitudes is still generally sparse, there is reason to believe that white attitudes have changed such that racial homogenization is no longer the inevitable outcome of residential diversity.

Lastly, metropolitan racial and ethnic composition underlies the possibility of place-level integration. The size of populations of color has long been recognized as a key determinant of segregation and discrimination. Metro areas with large communities of color experience greater segregation - whites fear neighbors of color as overall populations of color grow, a phenomenon known as "group threat" (Blalock 1967; Fussell 2014). For example, as populations of color become larger, whites believe they face declining housing values or greater exposure to crime, 
and thus implement strategies for rigid segregation. Empirically, the largest, most diverse metropolises are simultaneously some of the most segregated like New York and Los Angeles (Logan and Stults 2011). However, there is a tension between minority group threat and metro diversity because diversity and integration are clearly jointly related. By the numbers, there will be more chances for integration in metro areas with greater diversity. A diverse stock of metro area residents forms a basis for people of different races and ethnicities to live next to each other in the same communities. Integrated communities will not exist in metro areas where the populations are too homogenous to provide a foundation for integration.

\section{The local features of residential integration across spatial scales}

Beyond racial and ethnic composition, local environments of place, as well as the metropolitan areas and regions in which they are embedded, underlie integration. Established within the segregation literature, the place stratification and ecological perspectives frame the features of place that promote or obstruct integration across spatial scales. Broadly, the place stratification model argues that both legacies and contemporary experiences of discrimination generate residential distributions (Massey and Denton 1993). Ecological perspectives suggest that the social environment of place regulates residential patterns via place characteristics like region, demographic composition, and employment opportunities (Farley and Frey 1994). Place stratification and ecological models often overlap and point toward structural conditions that govern the housing market across places, within and between metro areas and regions.

Ecological theories link the economic base of place and employment opportunities with racial settlement patterns. Institutional hubs for the military, the public sector, and public universities appear to anchor diverse populations to place (Farley and Frey 1994). Integration within these institutions likely creates daily interracial contact between colleagues within and across rigid rank hierarchies and may facilitate cross-racial coexistence downstream within residential environments. The military and public sector show high levels of employment integration, even within positions of authority, with smaller racial and ethnic wage gaps compared to other sectors (Diprete and Soule 1986; Moskos and Butler 1996; Moulton 1990). In 2015, people of color composed $40 \%$ of the active duty force of the military, containing disproportionately large shares of blacks (17\%) and substantial shares of Latinxs $(12 \%)$ and Asians (4\%) (Parker, Cilluffo, and Stepler 2017). While university settings may not necessarily show employment integration, they maintain highly educated and transient populations (Farley and Frey 1994). This exposure to diversity may cultivate cosmopolitan communities that welcome integration even when nested in regions lacking diversity. For example, in 2010, Charlottesville, VA, home to the University of Virginia, was $66 \%$ white, while the greater MSA was 76\% white (author's calculations, Census 2010). Empirically, these hubs display both higher diversity and inverse relationships with segregation scores (Farley and Frey 1994; Lee and Sharp 2017).

Both place stratification and ecological approaches suggest that new housing stock is a key indicator for residential integration and differentiates the housing market across suburbs and the central city within a metro area. New housing stock moves beyond the reach of legacy segregation and reflects development under the Fair Housing Act. Where the history of legal segregation (e.g., redlining) defines the development of central cities, newer suburbs may facilitate integration by the nature of their new construction. Internal migrants and immigrants largely drive the recent diversification of suburbia and new development accommodates these arrivals. For example, "reverse migrations" to the South show that middle-class blacks with college degrees often choose to settle in newer suburbs (Lacy 2016). Census tract-level analyses 
find that new housing stock associates with increased neighborhood diversity and lower segregation scores (Crowder and South 2005; Farley and Frey 1994).

Place stratification theory suggests that metropolitan political fragmentation exacerbates segregation between places, while ecological theory suggests that it may support integrated communities. Political fragmentation refers to the proliferation of municipalities within a metro area and directly reflects suburbanization. Historically, "vanilla" suburbs use their legal autonomy to establish land-use regulations and zoning ordinances (e.g., low-density zoning) to exclude people of color, specifically blacks. Indeed, Lichter and colleagues (2015b) find that fragmentation associates with higher levels of metropolitan segregation. However, this association is primarily driven by between-place segregation, while fragmentation associates with declines in within-place segregation. The authors speculate that these results suggest withinplace homogenization, yet the findings also suggest that greater integration occurs within specific places, even as segregation increases across places. Through an ecological lens, a greater number of suburbs may provide new spaces for integration external to racially exclusive communities. For example, greater fragmentation may allow for more places to adopt higherdensity zoning, inclusionary zoning, or affordable housing policies, catching people of color excluded from predominantly white places.

Under place stratification theory, the availability of rental units and the prevalence of homeownership creates the place-level conditions conducive to integration. Homeownership represents the final stage of residential assimilation within communities, and racial disparities in homeownership vary markedly across metropolitan areas. For example, 75\% of whites and 25\% of blacks own homes in Minneapolis, while this gap narrows to $15 \%$ in Killeen, TX (McCargo and Strochak 2018). Homeownership disparities generally reflect disparities in wealth between whites and people of color as well as extensive antiblack discrimination in lending. An abundance of rental units may facilitate racial integration by promoting integration among people of different economic strata. In fact, within the neighborhoods literature, stably diverse census tracts tend to have lower homeownership rates than homogenous neighborhoods (Ellen, Horn, and O'Regan 2012) and black renters compared to homeowners show significantly lower segregation from whites (Friedman, Tsao, and Chen 2013).

Finally, the ecological approach suggests that larger regional geographies shape local environments favorable to integration. Coastal and southern border states operate as immigrant points of entry and are home to the most diverse metropolises in the nation (Lee, Iceland, and Sharp 2012). Multiethnic metropolitan areas along with Latinx/Asian metropolitan areas cluster largely on the East and West coasts and the Southern border, while predominantly white and black-white only metropolitan areas tend to situate further inland (Zhang and Logan 2016). These patterns condition how integration may occur more locally by shaping the stock of residents at the regional level.

\section{Hypotheses on residential integration}

Two dominant hypotheses concerning residential integration arise from the literature discussed above. First is the multiethnic hypothesis. Based on the buffering and multiethnic communities literatures, multiethnic places will show the highest probabilities of integration compared to bi-racial or bi-ethnic places. Blacks will show the lowest probabilities of integration, followed by Latinxs, and Asians will display the highest probabilities of integration. Latinxs and Asians will moderate black-white integration and the probabilities of black-white integration will increase with the addition of Asians and Latinxs. 
Second, is the local characteristics hypothesis. Based on both the place stratification and ecological frameworks, higher proportions of new housing and rental units, suburban status, hubs of federal funding (military, public sector, and university settings), and places within coastal/southern border states will be positively associated with residential integration. However, the two theories provide divergent hypotheses for political fragmentation: ecological theory suggests political fragmentation will enhance opportunities for residential integration while place stratification suggests that greater fragmentation will be negatively associated with residential integration.

\section{Data and methods}

The spatial unit of analysis—census places

To formally test the multiethnic and local characteristics hypotheses of metropolitan residential integration, this study draws on census places as the unit of analysis where places are defined as cities, suburbs, boroughs, towns, and villages (US Census Bureau 2015). These spatial units are ideal for the current analysis because places are consistent with the concept of place in which local areas compose "real" political and symbolic communities (Fowler, Lee, and Matthews 2016; Gieryn 2000; Hall, Tach, and Lee 2016; Lichter et al. 2015b). Most places are incorporated and correspond to governmental jurisdictions, and thus are responsible for policy and the provision of goods. Unincorporated places (i.e., Census-designated places; CDPs) are defined by the Census in cooperation with local officials.

Places are socially recognized communities that residents across a metropolitan area know by name and reputation (Bader and Krysan 2015; Krysan and Bader 2007). Residents personally identify with place reputation, which flags the racial climate of place. For example, Gardena is a suburb in Los Angeles County known for its high concentration of Japanese Americans and Shaker Heights is a suburb of Cleveland known for its black-white diversity. These recognizable racial contexts have material impacts that can promote integration or reproduce segregation. Places indicate public school systems and readily searchable real estate values. They form the basis for attraction or avoidance strategies in the housing search process and differentially influence residential mobility decisions across race and ethnicity (Bader and Krysan 2015; Krysan and Bader 2007).

Places are particularly useful for this study because suburbs are their own unit of analysis. Whereas conventional studies focus on urban neighborhoods, measured as census tracts, the suburbs fundamentally require a different mapping of social space. Rather than a collection of neighborhoods, residents understand suburbs as their own entities with names; for example, it is unlikely that metropolitan residents can identify census tracts within places like Gardena or Shaker Heights. Places coincide with suburbs as entities with service provision. When public transit lines extend into the suburbs for commuters, stations often carry the name of their suburb like Takoma Park, MD or South Orange, NJ. Further, places suit the social-spatial structure of the suburbs where residents generally are limited to private transportation. In this context, places circumscribe daily activities like grocery shopping and contain crucial institutions for racialized residential choice like public schools, business districts, and religious services. Because of these institutions, places provide a point of departure to understand the relationship between demographic residential integration and racial integration in other domains (e.g., education or employment) within the suburbs. 


\section{Defining and identifying racially integrated places}

Common metrics measuring racial and ethnic residential distributions are problematic for the positive study of integration. Integration has been defined a number of ways, and, in a research synthesis, Sin and Krysan (2015) refer to the study of integration as a "morass of measurement mayhem" (p. 473). The authors identify a tension between two dimensions of integration: 1) the absolute racial and ethnic composition of integration, and 2) how the composition of a place compares to the larger geography in which it is nested.

Studies focusing on a specific structure of integration typically use typologies of absolute cutoffs. For example, a space must be at least $10 \%$ black, Asian, Latinx, and white to be deemed integrated (e.g., Hall, Crowder, and Spring 2015). Absolute cutoffs benefit the study of integration because they partition the space of racial and ethnic structure into directly interpretable compositions. However, there is no consensus in the literature regarding which cutoffs to use. Furthermore, cutoff typologies expand multiplicatively with the addition of groups, quickly becoming analytically unwieldy. Within the national context, absolute cutoffs do not accommodate the uneven distributions of groups across metropolitan areas and across regions. For example, a typology deemed appropriate for greater Los Angeles (7\% black, 12\% Asian, and 36\% Latinx) likely will be inappropriate for greater Raleigh, North Carolina (20\% black, 4\% Asian, and 10\% Latinx) (U.S. Census Bureau 2017).

Other studies take a comparative approach, generally using "evenness" indices first popularized in segregation research like the Index of Dissimilarity (Massey and Denton 1993) or the information theory index (H) (Reardon and Firebaugh 2002). These indices compare the overall place composition with more local areas to measure how "evenly" diversity is spread throughout the place's geography. A place is completely residentially integrated when every subunit (i.e., tracts or blocks) displays the place's exact level of diversity, approximating an even dispersion of racial and ethnic groups. Alternatively, a place is maximally segregated when each subunit contains only one group.

Since comparative measures eschew cutoffs, they are flexible across places with different overall compositions; however, they are not without their issues. With comparative measures, the possibility of integration originates in the place-level race and ethnic composition. Therefore, if a place is dominated by one group, high levels of evenness do not necessarily constitute integration. For example, Rugh and Massey (2014) identify the metropolitan statistical areas (MSAs) with the lowest black-white dissimilarity in 2010: Missoula, MT, Provo, UT, and Boulder, Fort Collins, and Grand Junction, CO. Notably, the share of blacks in all these MSAs is less than 1\% (U.S. Census Bureau 2017). Despite high evenness, these MSAs do not map onto a concept of integration that requires substantial cross-racial interaction for both majority and minority groups. While blacks in these MSAs probably frequently interact with whites, the reverse is unlikely to be true in aggregate.

In this paper, I offset the weaknesses of absolute cutoffs and evenness approaches by combining the two. Because I posit that residential integration may only occur under conditions of diversity, I first impose an inclusion criterion that places may be at maximum $80 \%$ on racial or ethnic group over a 10 -year time horizon. ${ }^{1}$ This cutoff provides a range of places that are highly diverse to those that are moderately less diverse than the nation at large in 2010. Among this stably diverse sample, I calculate the comparative information theory index, allowing integration to occur across different racial and ethnic structures. This combination approach allows for a parsimonious way to identify stable integration amongst substantive diversity that is also flexible to multiethnic compositions across the nation. 
Data: To define stable integration, I draw on place-level racial and ethnic composition data from the 2000 and 2010 Decennial Censuses. I obtained these data, including shapefiles, from the National Historical Geographic Information System (NHGIS), which provides time series data standardized to 2010 geographies (Manson et al. 2017). I examine the following racial and ethnic categories: Latinx and non-Latinx black, Asian, Native American/Alaskan Native, white, and other. I start with 2000 data because the time period roughly marks the contemporary epoch with large Asian and Latinx populations across the nation in both cosmopolitan regions and new immigrant destinations. Rather than analyze trajectories of change, this method identifies communities that maintain stable integration

For sample selection, I start with all metropolitan census places with complete ACS data for the 2008-12 5-year estimates $(n=14,892)$. I break New York City into each borough due to its political structure. The $80 \%$ criterion excludes 11,107 places, of which $95 \%$ are predominantly white, $2 \%$ are predominantly black, and $3 \%$ are predominantly-Latinx. No places exhibit Asian dominance. Many predominantly white places show low to moderate $2010 \mathrm{H}$ scores, such as Vancouver, WA $(\mathrm{H}=0.15)$ and Fargo, ND $(\mathrm{H}=0.25)$. Predominantly black places include notably segregated cities like Detroit, MI, Gary, IN, and East St. Louis, IL. Most predominantly Latinx places situate within the South and Southwest, such as Laredo, TX, East Los Angeles, CA, and Tamiami, FL.

Methodology: Among the final analytic sample, I calculate $\mathrm{H}$, a commonly used index that measures the spatial evenness of racial and ethnic diversity among multiple groups (Reardon and Firebaugh 2002). H measures how closely the diversity of constituent subunits mirror the diversity of the place of interest. I use census blocks as the subunit for places, and thus, the comparison is between block diversity and overall place diversity. Diversity is defined as entropy (E):

$$
E=-\sum_{r=1}^{N} \pi_{r} \log \left(\pi_{r}\right)
$$

where $\pi_{r}$ is the place's share of race or ethnic group $r$. I calculate $E$ for each block $(i)$ to derive $E_{i}$. H compares $E$ and $E_{i}$ and is defined as

$$
H=\sum_{i=1}^{M} \frac{t_{i}\left(E-E_{i}\right)}{E T}
$$

where $t_{i}$ is the total population count in block $i$, and $T$ is the total population count of each place. The index ranges from 0 to 1 , where 0 indicates that the diversity of each block matches perfectly the overall place diversity (maximum integration) and 1 indicates that each block contains only one group (maximum segregation). Values above 0.4 are typically considered moderately-highly segregated and not integrated. For example, in this analysis of 2010, the cities proper of Chicago and Atlanta have $H$ values of 0.57 and 0.52 , respectively, suggesting low integration. I label a place as integrated if it falls within the bottom quartile of the sample $(\mathrm{H} \leq$ 0.14 for census years $)^{2}$

The final analytic sample reduces to 3,785 metropolitan places that show substantive diversity over the decade. This sample contains over $50 \%$ of the national metropolitan population in both 2000 and 2010 - approximately 113 million residents in 2000 and 124 million residents in 2010. Integration status shows stability among 763 places of a possible 946 places (81\%) that remained in the first quartile during the study period. These stably integrated places cover $20 \%$ of the final analytic sample and 15 million residents in 2010. Integrated places contain roughly $5.7 \%$ of the metropolitan population, and $10.7 \%$ and $11.4 \%$ of the analytic sample in 2000 and 
2010, respectively. Due to their very small shares in the sample, I exclude Native Americans from the proceeding analyses and focus only on blacks, Latinx, Asians, and whites. ${ }^{3}$

\section{Determinants of integration}

After identifying integrated places, I investigate key circumstances conducive to integration within diverse places. This cross-sectional analysis focuses on 2010 data with racial and ethnic composition variables from the 2010 Census and other place-based variables from the 2008-12 American Community Survey 5-year estimates (Manson et al. 2017). I regress the indicator of integration on several critical independent variables and potential confounders using logistic regression with generalized estimating equations. I cluster the variance at the MSA using the robust sandwich estimator. This estimator is referred to as robust because it provides reliable inference with imbalanced designs and potential misspecification of the covariance structure (Ziegler 2011). The racial and ethnic composition of places within MSAs, along with other variables, are likely correlated due to spatial proximity. I use the robust estimator because this spatial proximity of places varies widely across MSAs, especially after limiting the sample to diverse places. I exponentiate the parameter estimates and report the results in odds ratios to simplify interpretation.

To address localized spatial autocorrelation within MSAs, I construct a spatial lag that captures the number of neighboring places that are integrated. Using all metropolitan places (including predominantly one-group places), I derive the spatial lag variable based on the fivenearest places using distances between the central latitude-longitude coordinates of each place. I coerce symmetry (i.e., if place $i$ is neighbors with $j$, then $j$ must also be neighbors with $i$ ), so many places have greater than five neighbors. Of these neighbors, I sum the number that are integrated to generate a measure of spatial clustering with a range of 0 to 8 , where high values indicate high spatial clustering of integrated places and low values imply low spatial clustering.

Racial and ethnic composition: I classify the racial and ethnic composition of each place using the $25 \%$ criterion first proposed by Logan and Zhang (2010). I consider a place to have a substantial presence of a group if the share of residents in that place is at minimum $25 \%$ of their share in the total sample. The method posits that a group is substantively absent from a place if it does not meet this threshold. For example, in 2010, Latinxs composed $24.7 \%$ of the sample; I consider a place to have a substantial Latinx presence if it is at least $6.2 \%$ Latinx (i.e., $24.7 \% * 0.25)$. Using the $25 \%$ criterion, I create indicator variables for black, Latinx, Asian, and white presence. I parameterize multiethnic contexts to investigate buffering with separate black/Asian/white and black/Latinx/white interaction terms. ${ }^{4}$ Nativity may confound the relationship between racial and ethnic composition and residential integration. Therefore, I control for nativity, which is measured as the percent of residents that are foreign-born. I calculate metropolitan diversity as the entropy score (defined above) for each place's associated metropolitan area.

Local characteristics: Place-level characteristics include institutional hubs (military, public sector, and university settings), the share of renter-occupied housing, new housing stock, and geographic size. Following Lee and Sharp (2017), I classify a place as a military hub if the share of residents in the labor force employed in the Armed Forces is twice the national share. I use the same rule for civilian public sector employment (local, state, or federal employment) and public university enrollment. This approach yields institutional hub cutoffs of $1.4 \%, 29.8 \%$, and $41.7 \%$, respectively. ${ }^{5}$ I use the percentage of units that are renter-occupied to capture renters and the percentage of structures built after 1990 as a measure of new housing stock. I control for geographic size because larger places necessarily allow for greater spatial differentiation. I split 
the sample into quartiles by land area to control for this phenomenon while providing easily interpretable effects.

Metropolitan-level characteristics include central city/suburban status, political fragmentation, and size. I consider a place to be the central city if it has the largest population in the associated metropolitan area; all other places are considered suburbs. I use a measure of political fragmentation that relies on the share of residents belonging to different municipalities (Bischoff 2008; Crowder et al. 2012). ${ }^{6}$ This index calculates the probability that two residents from the same metropolitan area live in different places. Using the US Department of Agriculture 2013 Rural-Urban Continuum Codes (Economic Research Service 2015), I classify places as situated in a large MSA when the MSA contains at least 1 million residents. Medium metropolitan areas are those comprising 250 thousand to 1 million residents and small metropolitan areas are those comprising less than 250 thousand residents.

Lastly, I include an indicator for places in states on the east or west coasts or southern border because multiethnic areas are disproportionately located in these regions (Zhang and Logan 2016). I use this variable to account for unobserved regional level factors that might attract a number of racial and ethnic groups and concurrently influence residential integration. For ease of interpretation, I mean-center all continuous variables and scale percentage variables (nativity, renter-occupied units, political fragmentation, and new housing stock) to units of 10 percentage points.

\section{Results}

\section{The link between racial and ethnic composition and residential integration}

In this study, I set out to understand which racial and ethnic groups live near each other in cities and suburbs across the nation. The following results regarding the racial and ethnic composition of residential integration contain three central findings with implications for the American racial order. First, integration occurs least often in places with black presence, followed by Latinxs, and Asians live in integrated communities at the highest rates. Second, Asians substantially buffer black-white integration, while Latinx presence associates with only modest increases in black-white integration. Third, fully multiethnic places with all four groups show the highest rates of black-white integration.

The antiblack nature of racial settlement. Because legal racial segregation specifically targeted blacks in the US, I first explore how black presence in places associates with integration. Table 1 shows the frequency distribution of places typed by 2010 racial and ethnic composition across integration status. These findings resemble traditional segregation research in which blacks experience the most extreme forms of residential segregation from whites compared to other populations of color. Where integrated places occupy approximately $20 \%$ of the overall sample, bi-racial black-white places show an extremely low rate of integration (3\%) among eligible places, the lowest among all racial and ethnic combinations. For comparison, Asians show the highest rates of living in integrated communities; integrated places compose $62 \%$ of bi-racial Asian-white places. Bi-ethnic Latinx-white places, despite showing below sample-average representation, display a moderately higher rate of integration (16\%) compared to bi-racial black-white places.

[Table 1 about here]

The racial and ethnic composition of MSAs displays similar patterns where integrated places exhibit larger clusters in MSAs with smaller black populations. The first panel of Table 2 reports the results of the $10 \mathrm{MSAs}$ with the greatest number of integrated places (i.e., high 
integration MSAs). The second panel of Table 2 presents the MSAs with the largest number of diverse places that met the inclusion criterion but did not rank among the top 10 for integrated places (i.e., diverse-low integration MSAs). Integration by race and ethnicity at the metropolitan level continues to underscore the antiblack nature of segregation, where Asians and Latinxs experience greater exposure to whites. In the high integration MSAs, blacks show the highest differentiation from whites in integrated places compared to Asians and Latinxs. Some high integration MSAs show no to low representation of blacks in integrated places. For example, black communities are substantively absent among integrated places in Albuquerque, and blacks reside in less than 20\% of integrated places in Honolulu and Los Angeles. Asians outnumber blacks in integrated places in every MSA except Miami and DC, despite having the lowest representation in the overall sample by the $25 \%$ criterion, $(n=1,811$ for Asians; 2,537 for blacks). Latinxs outnumber blacks in integrated places in every MSA except DC and Seattle.

[Table 2 about here]

In contrast, the diverse-low integration MSAs are much blacker than the high integration MSAs, again speaking to the antiblack nature of racial settlement in the US. For example, Chicago, Atlanta, and Philadelphia are notably segregated black cities, while the greater metro areas maintain white majorities. On average, these diverse-low integration MSAs are $16 \%$ black while the high integration MSAs are $10 \%$ black.

The metropolitan analyses further confirm Asians' high access into integrated communities. The high integration MSAs are disproportionately western MSAs with large Asian populations. With the exceptions of Miami and Albuquerque, which both are $2 \%$ Asian, Asians live in more than $85 \%$ of integrated places among these MSAs. Notably, Honolulu, which is majority Asian and Pacific Islander, shows large clustering of integrated places despite its small size in terms of both population and number of places. Seattle is the whitest MSA among the high integration MSAs, and Asians are the largest population of color composing $12 \%$ of greater Seattle. By comparison, the diverse-low integration MSAs show relatively small shares of Asians. On average these MSAs are 4\% Asian. Houston is the most Asian MSA in this list and it is still only $7 \%$ Asian.

Latinxs fall in between blacks and Asians and similarly drive diversity in both the high integration MSAs and the diverse-low integration MSAs. At 16\% of the 2010 national population, Latinxs on average compose $28 \%$ of the high integration MSAs and $25 \%$ of the diverse-low integration MSAs. Despite Albuquerque's small size and low diversity, it appears among the high integration MSAs because integration occurs entirely across places with only Latinxs and whites present. Honolulu and Seattle display low rates of integration for Latinxs $(23 \%, 59 \%$ respectively), and are the only MSAs that contain Latinx populations substantially lower than the national average.

The roles of buffering and multiethnic communities in facilitating integration. Collectively, these results specifically support the role of Asian buffering, while, in contrast, evidence for Latinx buffering is more modest. Returning to Table 1, when Asians are present, the rate of integration in places with blacks and whites grows to $21 \%$ (black-Asian-white places). Black-Latinx-white places, however, show only a slightly higher rate of integration compared to black-white places (6\% vs. 3\%).

Beyond individual group buffering, the combination of both Latinxs and Asians dramatically improves black-white integration. The most multiethnic settings, black-LatinxAsian-white places, compose the only place type where black presence displays an overrepresentation of integration (34\%) compared to the overall sample. Consistent with the 
multiethnic hypothesis, highly diverse places may reinforce stable integration when no group maintains social and political dominance, allowing blacks to coexist among whites without rapid change. This transformation of multigroup race relations moves beyond the additive components of Latinx and Asian buffering, which both show substantially lower rates of black-white integration.

The metropolitan results in Table 2 continue to emphasize how multigroup diversity shapes integration. Many of the high integration MSAs are generally among the most racially diverse areas in the nation with smaller than average white populations and large shares of each population of color. The majority of the high integration MSAs show no racial majority, and several show pluralities by populations of color: Los Angeles, Miami, Honolulu, Riverside, and Albuquerque. Seattle and Sacramento are the only MSAs in the list with white majorities, and Seattle is the only MSA with a white population greater than the national share. In comparison, many diverse-low integration MSAs lean toward bi-racial or bi-ethnic compositions (e.g., San Antonio, Richmond, Austin, and Phoenix). Eight out of 10 of these MSAs display white majorities, compared to only 2 among the high integration MSAs.

Multivariate analysis. Lastly, I turn to results generated by multivariate logistic regression analysis to understand the association between racial and ethnic composition and residential integration, net of other place-based and metropolitan characteristics, geographic nesting within MSAs, and localized spatial autocorrelation. Figure 1 reports the predicted probabilities of integration by multiethnic place type focusing on places where blacks and whites live together (for all parameter estimates, see Appendix Table A1). Model 1 presents the simplest model with only the main effects for the presence of each racial and ethnic group. Model 2 interacts black, Asian, and white presence as a test of Asian buffering; Model 3 interacts black, Latinx, and white presence as a test of Latinx buffering; and lastly, Model 4 includes both interaction terms for the fully multiethnic model.

[Figure 1 about here]

In general, the overall main effects estimates in Model 1 support the descriptive evidence provided in Tables 1-3: black-white integration is rarest without the presence of Asians; Latinxs show limited buffering; and integration is most common in fully multiethnic communities. In black-white places, the predicted probability of integration is $13.3 \%$ and $15.1 \%$ in black-Latinxwhite places. But in places with Asians, the predicted probability more than doubles to $33.9 \%$ in black-Asian-white places and 37.2\% in black-Latinx-Asian-white places. These results clearly confirm that blacks access integrated communities at the lowest rates among all populations of color and point to a continuing pattern of antiblack racism and racialization throughout the nation. Further, these main effects estimates suggest a special role of Asians in facilitating residential integration.

These conclusions are reinforced after the addition of the Asian and Latinx buffering terms in Model 2 to 4 . When all compositional variables are taken together, these results indicate that Asian presence fundamentally alters racial dynamics of place and the most multiethnic places are associated with the most integrated outcomes, even after controlling for key place and metropolitan characteristics. The four groups together synergistically produce integrated communities at higher rates than any other black-white permutation. In Model 2, the gap in predicted probabilities between communities with Asians (black-Latinx-Asian-white: 38\%; black-Asian-white: $36.2 \%$ ) and those without Asians (black-white: 11.6\%; black-Latinx-white: $12.4 \%$ ) widens. Beyond the main effects, Asian buffering accounts for roughly 4 percentagepoints of this gap, representing a nontrivial increase in black-white cross-racial exposure. In 
Model 3, the Latinx buffering term increases the predicted probability in black-Latinx-white places to $17.1 \%$, a 2-percentage point increase from Model 1, and 5.5-percentage points higher than black-white places. While this probability is much smaller compared to Asians, it still suggests that Latinxs as a third party may moderate and improve integration among blacks and whites. Lastly, in Model 4 with both interaction terms, black-Latinx-Asian-white places exhibit the highest predicted probability of integration among all the models (40.1\%). However, the Asian buffering interaction term becomes only marginally significant at the 0.05 level (Odds Ratio 95\% CI: 0.98, 2.49) and the substantive outcome differs modestly from Model 3.

\section{The suburbanization and local economies of residential integration}

The results thus far discuss which racial and ethnic groups are integrating with each other with special attention to black-white integration. Beyond population composition however, the broader social structure of places influences these racial settlement patterns and condition the possibility for residential integration to arise. Using the framings of place stratification and ecological theories, I discuss several critical features of places previously established to explain how distinct racial and ethnic groups relate to each other in space. This section specifically highlights the importance of suburbs and economies fueled by the federal government in supporting the rise of residential integration.

Table 3 reports the descriptive statistics of key place-based characteristics across integration status. This analysis supports the proposed hypothesis that integrated places are disproportionately located in suburbs. Integrated places are almost entirely suburban (99.5\%) while diverse/not integrated places show a larger share of central cities (91.9\% suburbs). Despite high levels of diversity, segregated neighborhoods arising from redlining and white flight still define the central city.

[Table 3 about here]

Contrary to the place stratification model and consistent with ecological theory, integrated places exhibit higher representation in more fragmented metro areas on average $(0.74$ vs. 0.63). For context, average MSA fragmentation in the sample equals 0.83 while the IQR is 0.43-0.67. I calculate fragmentation as the probability that two residents live in the same place. The size of the central city heavily influences this probability. MSAs with smaller central cities and expansive suburbs will appear more fragmented than large cities with concentric circle industrialization and development. In fact, in Table 2, many of the high integration MSAs are large MSAs with small central cities. Greater DC cuts across political boundaries (DC, Maryland, and Virginia) and has a sprawling spatial structure where the population is divided among many suburban municipalities with only $10 \%$ of the population living in the city.

By comparison, the diverse-low integration MSAs have an average fragmentation of 0.61 , substantially lower than the high integration MSAs (0.83). Many of these MSAs have larger central city populations relative to the overall MSA. For example, the cities of Chicago, Houston, Philadelphia, Dallas, and Austin have roughly 1 million residents or more. Since fragmentation reflects suburbanization, this structure makes it such that smaller proportions of residents will access integrated communities in the suburbs. Whereas prior research finds that fragmentation exacerbates segregation via racial exclusion across communities, this analysis supports the ecological theory. While segregation increases across places, certain places support integrated spaces as people of color move into the suburbs.

Lastly, the institutional hub variables support the proposed ecological hypotheses: economies created by the government through the military, public sector, and public universities disproportionately support integrated communities. Military and public sector hubs display 
striking overrepresentation among integrated places (26\% vs. $8 \% ; 15 \%$ vs. $7 \%$ ). Evidence is weaker for university hubs which compose a modestly larger share of integrated places (5\% vs. $4 \%$ ). Institutional hubs may explain the high rates of integration among the most integrated MSAs. Appendix Table A2 describes how these hubs cluster within MSAs. As the nation's capital, greater DC figures prominently in these lists, and ranks first with 58 military hubs and 41 public-sector hubs. Honolulu contains 37 military hubs and 9 public-sector hubs. Seattle maintains 14 military hubs and Albuquerque has 15 public sector hubs.

Employment opportunities have huge ramifications for residential choice and these hubs seem to override the role of population composition and other characteristics in influencing integration. For example, these hubs likely impact clustering in Albuquerque, Honolulu, and Seattle, despite little multiethnic diversity across the four groups. In the face of blacks' low access to integrated communities nationally, over $90 \%$ of DC's integrated places include substantial black populations. Further, institutional hubs compose all four integrated central cities. Military hubs compose 3 of these central cities: Hinesville, GA (Fort Stewart); Jacksonville, NC (Camp Lejeune and New River Air Station); and Killeen, TX (Fort Hood). The last integrated central city is San Luis Obispo, CA, a university hub home to the California Polytechnic State University.

Multivariate analyses: Finally, I turn to results produced by multivariate logistic regression analysis to examine how these place-based characteristics associate with integration after controlling for population composition, nesting within MSAs, and spatial autocorrelation. Figure 2 reports the odds ratios generated by Model 4, the model with both Asian and Latinx buffering terms. ${ }^{7}$ These results reinforce the descriptive evidence presented in Table 3 . As hypothesized by both ecological and place stratification theories, suburbs show the strongest positive association of all parameters with a dramatic odds ratio of 7.18 (95\% CI; 2.75, 18.7). Suburbs clearly support integrated communities beyond the central city, even after controlling for other factors like new development and political fragmentation. While folk knowledges assume that cities are the containers for the highest levels of cosmopolitan diversity, this finding supports recent research documenting suburbs as the leading spaces of American diversification and residential integration.

[Figure 2 about here]

Providing evidence for the ecological perspective, metropolitan political fragmentation shows a strong positive association with the odds of integration. A $10 \%$ increase in fragmentation associates with a $15 \%$ increase in the odds of integration. Moving from the first quartile (0.52) to the third quartile (0.83) is equivalent to an increase in the odds of integration by $54 \%\left(1.15^{(0.83-0.52) * 10}=1.54\right.$, where fragmentation is scaled to 10 percentage-point units). More suburbanized metro areas support more integrated communities. On the surface, this finding seems to contradict prior research indicating that higher fragmentation associates with greater segregation between places within a metropolitan area. However, after excluding racially homogenous places in this sample, pockets of integration may arise in places that actively attract people of color by a welcoming environment or, at minimum, catch those excluded from racially exclusive places.

As hypothesized, new housing stock shows a positive association with the odds of integration - moving from the $1^{\text {st }}$ quartile $(12 \%)$ to the $3^{\text {rd }}$ quartile $(38 \%)$ associates with an increase of the odds of integration by $44 \%\left(1.15^{(0.38-0.12) * 10}=1.44\right.$, where percent new housing is scaled to 10 percentage-point units). New housing stock supports both ecological and place stratification perspectives - new housing provides openings for new arrivals and reflects 
development after the passage of anti-discrimination legislation. Further, new housing differentiates middle- and outer-ring suburbs from the central city and inner-ring suburbs, suggesting a flow of diversity far from the central city.

After suburbanization, the economic base of place highly influences the possibility for residential integration. Military hubs show a large positive odds ratio of 2.99 (95\% CI: 2.22 , 4.05). Public sector hubs also associate with increased odds of integration by more than 2-times (OR: 2.03, 95\% CI: 1.42, 2.90), and university hubs associate with an increased odd of integration by 1.77 times (95\% CI: 1.15, 2.73). These strong associations provide further support for prior structural-ecological work that argues that these institutions are inversely related to segregation. While these results do not suggest causality, they indicate an association between employment integration and residential integration. These institutional hubs attract racially and ethnically diverse populations and undergird residential integration in unexpected geographies. Military hubs like Schofield Barracks and Kaneohe Marine Corps Station compose the only black-Latinx-Asian-white integrated places in the Honolulu metro area, which is defined by a largely Asian/white racial composition. Integrated university hubs include places external to diverse MSAs like College, AK (University of Alaska-Fairbanks) and Kennesaw, GA (Kennesaw State University).

Integrated places display substantial spatial autocorrelation and cluster together within metropolitan areas. Having one integrated neighbor ( $3^{\text {rd }}$ quintile) increases the odds of integration by $35 \%$ while having two integrated neighbors ( $4{ }^{\text {th }}$ quintile) increases the odds of integration by $82 \%\left(1.35^{2}=1.82\right)$. While places differentiate metropolitan housing markets, a spatial scale between the place and MSA operates to create an uneven distribution of integration within MSAs. For example, no-racial-majority, integrated Rodeo in the East Bay of San Francisco has five integrated neighbors, while white-majority, not-integrated San Rafael in Marin County has no integrated neighbors.

Some additional variables fail to support the proposed hypotheses. MSA racial and ethnic diversity shows almost no effect on the odds of integration $(\mathrm{OR}=0.98)$. Places within coastal and southern border states show a moderate, yet non-significant positive association $(\mathrm{OR}=1.40$, 95\% CI: 0.89, 2.18). Finally, percent renter-occupied units shows a completely immaterial association $(\mathrm{OR}=1.00)$, suggesting that residential integration is independent of homeownership.

\section{Conclusion and discussion}

The empirical aim of this paper was to examine the relatively widespread nature of residential integration. Where past research focuses on the census tract, I identified racially integrated places among socially and politically meaningful spatial units across the nation. While prior studies generally meet declining segregation with skepticism due to whites' extensive aversion to people of color, I find promising evidence that millions of Americans live in stable, multiethnic communities that are not amid transition over a 10 -year time horizon. This analysis continues to highlight the antiblack nature of racial settlement in the US where blacks show the lowest representation in integrated communities. Further, integration is specifically supported by Asian presence and multiethnic compositions and disproportionately occurs within suburbs, fragmented metropolitan areas, and economies fueled by the federal government. Whereas racial segregation is intrinsic to the inequitable distribution of resources in the United States, $21^{\text {st }}$ century integration may offer a new avenue for race relations - one that requires new theory especially at a time of increasing diversity with explicit national racial hostility. 
Recent studies document intransigent metropolitan segregation (Massey 2015) and simultaneously point to the emergence of racially diverse census tracts across the nation (Bader and Warkentien 2016; Logan and Zhang 2010; Zhang and Logan 2016). However, past research offers little evidence regarding social and political geographies and leaves unanswered important questions regarding the spatial structure of integration in suburbs as well as insight on the placelevel and metropolitan conditions that shape integration. Shifting the geographic unit to a socially meaningful construction of place changes our understanding of integration to a phenomenon that co-occurs with entrenched metropolitan segregation. Many high integration MSAs are concurrently some of the most segregated when using MSAs as the unit of analysis. For example, as of 2010, greater DC's black-white dissimilarity was 0.64 (i.e., 64\% of the black and white population would have to move census tracts to achieve complete integration) and DC displays dramatically increasing Latinx-white dissimilarity in recent decades $(1980: \mathrm{D}=0.32$, 2010: $\mathrm{D}=0.48$ ) (Logan and Stults 2011). However, concurrently, DC's suburbs show the highest frequency of integration across all four racial and ethnic groups when using places as the unit of analysis.

These analyses reveal familiar patterns of the antiblack nature of segregation as well as the possibility of black-white integration via multiethnic compositions. Blacks have the lowest probability of living in integrated places with whites. However, when blacks and whites live alongside Asians, the probabilities of integration increase three to four-fold, generally representing an increase between black-white interracial contact. Communities with all four groups together associate with the highest probabilities of integration, suggesting that multiethnic environments alter race relations in ways that promote stable integration beyond individual group buffering, such as planning dissonance (Lumley-Sapanski and Fowler 2017).

The difference between Latinx and Asian buffering points out distinctions in the American racial order. Where prior research articulates the antiblack color line as the exception (Parisi, Lichter, and Taquino 2011), this study alternatively suggests Asians as the "exceptional" population of color as blacks and Latinxs experience more rigid racial boundaries from whites. Despite large population growth in recent decades among Asians, whites show a disproportionate propensity for living with Asians in the same communities. Metropolitan areas with relatively large Asian populations such as Honolulu and Seattle show high frequencies of place-level integration.

In contrast, Latinx presence, while statistically significant, displays a small buffering effect on black-white integration. These results may reflect increasing segregation for certain segments of the Latinx population and growth in new immigrant destinations, which display markedly high residential segregation (Lichter, Parisi, and Taquino 2016). Further, Latinxs may experience increased group threat as they are now the largest population of color. Recent declines in black-Latinx segregation exceed declines in Latinx-white segregation, suggesting increasing incorporation into black communities (Lichter, Parisi, and Taquino 2015a). Lastly, the US's proximity to Latin America and continual immigrant replenishment emphasize ethnic boundaries even for later-generation residents (Jiménez 2008).

Several critical place-based factors play prominent roles in facilitating integration with implications for ecological and place stratification theories. Suburbs almost completely compose integrated places. Political fragmentation may increase overall metropolitan segregation via exclusionary ordinances (Crowder et al. 2012; Lichter et al. 2015b); however, where many suburbs preserve their white homogeneity, others in juxtaposition maintain their cosmopolitan identity as racial and ethnic diversity increasingly moves further from the city core. New housing 
stock allows places to transcend legacy segregation as the US grows more diverse, provides space for expanding suburban communities of color and gives people of color access to better quality housing alongside whites. Fundamentally, the local characteristics of place must go beyond the reach of enduring racial discrimination for residential integration to occur.

Hubs of government funding (i.e., military, public sector employment, and public universities) show particularly strong associations with integration. Employment has massive consequences for residential choice-people will try to live near where they work to reduce commute times and improve quality of life. Employment integration across occupational rank within these middle-class sectors facilitates cross-racial contact within institutional space, while simultaneously mooring diverse populations to place. Integrated economies thus provide openings for integrated communities to persist.

Remarkably, homeownership and renting displays almost no effect with integration. This result is consistent with segregation research that finds little evidence that class attenuates residential segregation. Black-white segregation is generally independent of income (Charles 2003) and homeowning blacks experience higher levels of segregation than their renting counterparts (Friedman et al. 2013). Furthermore, using a place-based approach, Lichter and colleagues (2015b) find that black-white income inequality is immaterial to metropolitan segregation. Beyond other place-based characteristics included in this analysis, it seems that the wealth of people of color will not dismantle the structure of racial segregation.

This study provides a point of departure for future research. It bridges conventional studies of multiethnic census tracts with recent research that asserts the importance of the political and social boundaries of place (Lichter et al. 2015b). It provides a spatial analysis that separates cities and suburbs of varying sizes. Taking this approach reveals that suburbs play a large and typically underappreciated role in creating integrated spaces among larger metropolitan segregation. As suburbs generally are responsible for the provision of services, rather than constituent census tracts, this analysis supplies the geographic basis for understanding the downstream effects of residential integration such as school district integration or healthcare access. Qualitative studies of nominally integrated neighborhoods within highly segregated cities document patterns of micro-segregation within activity spaces (Tach 2014); however, the current study suggests that it is time to look beyond the central city to understand how residential dynamics impact social integration.

This study presents new suburban sites to understand how multiethnic regimes negotiate stable integration and continue to attract and maintain diverse populations. While segregation within the white power structure deeply harms the opportunity structures of people of color, understanding the contextual factors that create residential integration may help facilitate crossracial coexistence, eliminate the problems of white disinvestment from communities of color, and improve the overall wellbeing of populations of color. 


\section{Endnotes}

1. The appendix includes sensitivity analyses using a $70 \%$ cutoff. Theoretically, this specification is more conservative because of the greater diversity of the overall sample. For context, non-Latinx whites compose $63.7 \%$ of the nation. These findings show that regression estimates' magnitude and direction are robust to this cutoff specification. However, despite similar effect sizes, some estimates lose statistical significance at the 0.05 level, likely due to the reduction of nearly $40 \%$ of the sample. See Appendix Table B1.

2 . I conduct a sensitivity analysis that defines integration with a more liberal cutoff - the first tertile marker, 0.17 in both years. The magnitude and direction of regression parameter estimates are robust to this specification. See Appendix Tables B1.

3. Native Americans compose approximately $0.5 \%$ of the sample. Only 155 places contain Native American shares greater than 5\%. For comparison, the next smallest category, Asians, constitute shares of at least 5\% for 1,007 places in the sample. While this analysis excludes Native Americans, Native Americans disproportionately contribute to diversity in rural America. The history of Native American "termination" by assimilation provides a contrasting theoretical framework for residential integration (i.e., integration as the result of discrimination and genocide). Future research may look to this often-understudied group to further illuminate how spatial distributions reflect heterogeneous race relations and resulting residential settlement patterns.

4. I conducted a sensitivity test using a model with a black*Latinx*Asian*white interaction term to specifically parameterize the most multiethnic places; however, this more complicated model did not improve overall model fit and provided similar results as the more parsimonious model with the separate black*Latinx*white and black*Asian*white interactions.

5. I use this measurement strategy to include places that cluster around military installations. My intent is to capture economies linked to the military beyond the formal installation. Given the relatively small cutoff for military hubs, I conducted a sensitivity analysis using military installations only, which produced an odds ratio estimate of more than 11-times the magnitude of the reported results (Appendix Table B1). I relaxed this criterion to label hubs as places where $10 \%$ of the labor force was in the Armed Forces - the resulting odds ratio was more than double the magnitude of the reported results. Hence, the reported results below provide a conservative estimate of the association between integration and military presence.

6. I calculate fragmentation as $\sum_{i=1}^{k} P_{i}\left(1-P_{i}\right)$, where $P_{i}$ is the proportion of residents in the metropolitan area living in place $i$.

7. I present estimates from Model 4 because the estimates for these place characteristics are relatively invariant across the four models. For a table of the results of all four models, see Appendix Table A1. 


\section{References}

Bader, Michael D. M. 2016. Diversity in the D.C. Area: Findings from the 2016 D.C. Area Survey. 14. Washington, DC.

Bader, Michael D. M. and Maria Krysan. 2015. "Community Attraction and Avoidance in Chicago." The ANNALS of the American Academy of Political and Social Science 660(1):261-81.

Bader, Michael D. M. and Siri Warkentien. 2016. "The Fragmented Evolution of Racial Integration since the Civil Rights Movement." Sociological Science 3:135-66.

Bischoff, Kendra. 2008. "School District Fragmentation and Racial Residential Segregation." Urban Affairs Review 44(2):182-217.

Blalock, Hubert M. 1967. Toward a Theory of Minority Group Relations. New York: Wiley.

Boustan, Leah Platt. 2010. "Was Postwar Suburbanization 'White Flight'? Evidence from the Black Migration.” Quarterly Journal of Economics 125(1):417-43.

Brown-Saracino, Japonica. 2009. A Neighborhood That Never Changes: Gentrification, Social Preservation, and the Search for Authenticity. Chicago, IL: University of Chicago Press.

Charles, Camille Z. 2003. "The Dynamics of Racial Residential Segregation." Annual Review of Sociology 29(1):167-207.

Crowder, Kyle, Jeremy Pais, and Scott J. South. 2012. "Neighborhood Diversity, Metropolitan Constraints, and Household Migration.” American Sociological Review 77(3):325-53.

Crowder, Kyle and Scott J. South. 2005. "Race, Class, and Changing Patterns of Migration between Poor and Nonpoor Neighborhoods." American Journal of Sociology 110(6):171563.

Diprete, Thomas A. and Whitman T. Soule. 1986. "The Organization of Career Lines: Equal Employment Opportunity and Status Advancement in a Federal Bureaucracy." American Sociological Review 51(3):295-309.

Economic Research Service. 2015. "Rural-Urban Continuum Codes." USDA Economic Research Service. Retrieved April 6, 2018 (https://www.ers.usda.gov/data-products/rural-urbancontinuum-codes/).

Ellen, Ingrid Gould, Keren Horn, and Katherine O'Regan. 2012. "Pathways to Integration: Examining Changes in the Prevalence of Racially Integrated Neighborhoods." Cityscape 14(3):33-53.

Farley, Reynolds and William H. Frey. 1994. "Changes in the Segregation of Whites from Blacks During the 1980s: Small Steps Toward a More Integrated Society." American Sociological Review 59(1):23-45.

Flippen, C. 2004. "Unequal Returns to Housing Investments? A Study of Real Housing Appreciation among Black, White, and Hispanic Households." Social Forces 82(4):152351.

Fowler, Christopher S., Barrett A. Lee, and Stephen A. Matthews. 2016. "The Contributions of Places to Metropolitan Ethnoracial Diversity and Segregation: Decomposing Change Across Space and Time." Demography 53(6):1955-77.

Frey, William H. 2018. Diversity Explosion: How New Racial Demographics Are Remaking America. Washington, DC: Brookings Institution Press.

Friedman, Samantha, Hui shien Tsao, and Cheng Chen. 2013. "Housing Tenure and Residential Segregation in Metropolitan America." Demography 50(4):1477-98.

Fussell, Elizabeth. 2014. "Warmth of the Welcome: Attitudes Toward Immigrants and Immigration Policy in the United States." Annual Review of Sociology 40(1):479-98. 
Gibson, Campbell and Kay Jung. 2005. Historical Census Statistics On Population Totals By Race, 1790 to 1990, and By Hispanic Origin, 1970 to 1990, For Large Cities And Other Urban Places In The United States.

Gieryn, Thomas F. 2000. "A Space for Place in Sociology." Annual Review of Sociology 26(1):463-96.

Hall, Matthew, Kyle Crowder, and Amy Spring. 2015. "Neighborhood Foreclosures, Racial/Ethnic Transitions, and Residential Segregation." American Sociological Review 80(3):526-49.

Hall, Matthew, Laura Tach, and Barrett A. Lee. 2016. "Trajectories of Ethnoracial Diversity in American Communities, 1980-2010." Population and Development Review 42(2):271-97.

Humes, Karen R., Nicholas a. Jones, and Roberto R. Ramirez. 2011. Overview of Race and Hispanic Origin: 2010.

Jackson, Kenneth T. 1987. Crabgrass Frontier: The Suburbanization of the United States. Oxford: Oxford University Press.

Jiménez, Tomás R. 2008. "Mexican Immigrant Replenishment and the Continuing Significance of Ethnicity and Race." American Journal of Sociology 113(6):1527-67.

Kneebone, Elizabeth and Natalie Holmes. 2015. The Growing Distance Between People and Jobs in Metropolitan America. Washington, DC.

Krysan, Maria and Michael D. M. Bader. 2007. "Perceiving the Metropolis: Seeing the City through a Prism of Race." Social Forces 86(2):699-733.

Lacy, Karyn R. 2016. "The New Sociology of Suburbs: A Research Agenda for Analysis of Emerging Trends." Annual Review of Sociology 42(1):369-84.

Lee, Barrett A., John Iceland, and Gregory Sharp. 2012. Racial and Ethnic Diversity Goes Local: Charting Change in American Communities Over Three Decades.

Lee, Barrett A. and Gregory Sharp. 2017. "Ethnoracial Diversity across the Rural-Urban Continuum." The ANNALS of the American Academy of Political and Social Science 672(1):26-45.

Lichter, Daniel T., Domenico Parisi, and Michael C. Taquino. 2015a. "Spatial Assimilation in U.S. Cities and Communities? Emerging Patterns of Hispanic Segregation from Blacks and Whites." The ANNALS of the American Academy of Political and Social Science 660(1):3656.

Lichter, Daniel T., Domenico Parisi, and Michael C. Taquino. 2015b. "Toward a New MacroSegregation? Decomposing Segregation within and between Metropolitan Cities and Suburbs." American Sociological Review 80(4):843-73.

Lichter, Daniel T., Domenico Parisi, and Michael C. Taquino. 2016. "Emerging Patterns of Hispanic Residential Segregation: Lessons from Rural and Small-Town America." Rural Sociology 81(4):483-518.

Logan, John R., Elisabeta Minca, and Sinem Adar. 2012. "The Geography of Inequality: Why Separate Means Unequal in American Public Schools." Sociology of Education 85(3):287301.

Logan, John R. and Brian J. Stults. 2011. The Persistence of Segregation in the Metropolis: New Findings from the 2010 Census.

Logan, John R. and Charles Zhang. 2010. "Global Neighborhoods: New Pathways to Diversity and Separation." American Journal of Sociology 115(4):1069-1109.

Lumley-Sapanski, Audrey and Christopher S. Fowler. 2017. "'Planning Dissonance' and the Bases for Stably Diverse Neighborhoods: The Case of South Seattle." City and Community 
16(1):86-115.

Maly, Michael T. 2005. Beyond Segregation: Multiracial and Multiethnic Neighborhoods in the United States. Temple Uni. Philadelphia.

Manson, Steven, Jonathan Schroeder, David Van Riper, and Steven Ruggles. IPUMS National Historical Geographic Information System: Version 12.0 [Database]. Minneapolis: University of Minnesota. 2017. http://doi.org/10.18128/D050.V12.0.

Massey, Douglas S. 2015. "The Legacy of the 1968 Fair Housing Act." Sociological Forum 30(S1):571-88.

Massey, Douglas S. and Nancy A. Denton. 1993. American Apartheid. Cambridge, MA: Harvard University Press.

McCargo, Alanna and Sarah Strochak. 2018. Mapping the Black Homeownership Gap.

Moskos, Charles C. and John S. Butler. 1996. All That We Can Be: Black Leadership and Racial Integration the Army Way. New York: Basic Books.

Moulton, Brent R. 1990. "A Reexamination of the Federal-Private Differential in the United States.” Journal of Labor Economics 8(2):270-93.

Nyden, Philip, John Lukehart, Michael T. Maly, and William Peterman. 1998. "Neighborhood Racial and Ethnic Diversity in U.S. Cities." Cityscape 4(2):1-17.

Parisi, Domenico, Daniel T. Lichter, and Michael C. Taquino. 2011. "Multi-Scale Residential Segregation: Black Exceptionalism and America's Changing Color Line.” Social Forces 89(3):829-52.

Parisi, Domenico, Daniel T. Lichter, and Michael C. Taquino. 2015. "The Buffering Hypothesis: Growing Diversity and Declining Black-White Segregation in America's Cities, Suburbs, and Small Towns?" Sociological Science 2:125-57.

Parker, Kim, Anthony Cilluffo, and Renee Stepler. 2017. 6 Facts about the U.S. Military and Its Changing Demographics. Washington, DC.

Reardon, Sean F. and Glenn Firebaugh. 2002. "Measures of Multigroup Segregation." Sociological Methodology 32(1):33-67.

Rugh, Jacob S. and Douglas S. Massey. 2014. "Segregation in Post-Civil Rights America." $D u$ Bois Review: Social Science Research on Race 11(02):205-232.

Sin, Ray and Maria Krysan. 2015. "What Is Racial Residential Integration? A Research Synthesis, 1950-2013." Sociology of Race and Ethnicity 1(4):467-74.

Tach, Laura. 2014. "Diversity, Inequality, and Microsegregation: Dynamics of Inclusion and Exclusion in a Racially and Economically Diverse Community." Cityscape 16(3):13-45.

U.S. Census Bureau. 2017. "QuickFacts from the US Census Bureau." Retrieved September 22, 2017 (https://www.census.gov/quickfacts).

US Census Bureau. 2015. "2010 Geographic Terms and Concepts - Census Divisions and Census Regions." Geographic Terms and Concepts - Census Divisions and Census Regions. Retrieved May 11, 2018 (https://www.census.gov/geo/reference/gtc/gtc_ct.html).

Wilson, Jill H. and Audrey Singer. 2011. Immigrants in 2010 Metropolitan America: A Decade of Change. Washington, DC.

Zhang, Wenquan and John R. Logan. 2016. "Global Neighborhoods: Beyond the Multiethnic Metropolis." Demography 53(6):1933-53.

Ziegler, Andreas. 2011. Generalized Estimating Equations. Vol. 204. New York, NY: Springer New York. 


\section{Tables}

Table 1 . Frequency distribution of places (n) by multiethnic place type ( $25 \%$ criterion) and integration status in the 2010 Census.

\begin{tabular}{lccc}
\hline & Diverse/not integrated & Integrated & Integrated (\%) \\
\hline A & 3 & 9 & 75 \\
AW & 36 & 59 & 62 \\
BA & 2 & 1 & 33 \\
BAW & 163 & 44 & 21 \\
BL & 36 & 5 & 12 \\
BLA & 26 & 6 & 19 \\
BLAW & 621 & 318 & 34 \\
BLW & 547 & 38 & 6 \\
BW & 709 & 21 & 3 \\
L & 6 & 1 & 14 \\
LA & 7 & 7 & 50 \\
LAW & 347 & 162 & 32 \\
LW & 460 & 89 & 16 \\
W & 59 & 3 & 5 \\
\hline Total & 3022 & 763 & 20 \\
\hline
\end{tabular}

Note: $\mathrm{A}=$ Asian, $\mathrm{B}=$ Black, $\mathrm{L}=$ Latinx, $\mathrm{W}=$ White. Asian-alone place types have large multiracial populations and completely exist within the Honolulu metro area. Latinx-alone place types are located in the Southwest and West; 6 have large Native American populations and the last has a multiracial population. White-alone place types typically have large Native American populations and $77 \%$ of these places are in Oklahoma. 
Table 2. The Racial and Ethnic Composition of the 10 Most Integrated MSAs by Count of Integrated Places and the 10 Most Diverse MSAs that did not Rank among the Top 10 (2010 Census)

\begin{tabular}{|c|c|c|c|c|c|c|c|c|c|c|c|c|c|c|}
\hline \multirow[b]{2}{*}{ MSA } & \multicolumn{3}{|c|}{ Places (n) } & \multirow{2}{*}{$\begin{array}{c}\text { Pop. } \\
\text { (millions) }\end{array}$} & \multirow{2}{*}{$\begin{array}{c}\text { MSA } \\
\text { Fragmentation }\end{array}$} & \multicolumn{4}{|c|}{$\begin{array}{c}\text { Integrated by group presence } \\
\text { (n, } 25 \% \text { criterion })\end{array}$} & \multicolumn{5}{|c|}{ Race and ethnic composition (\%) } \\
\hline & Integrated & Sample & MSA & & & Black & Latinx & Asian & White & Black & Latinx & Asian & White & Diversity \\
\hline \multicolumn{15}{|c|}{ High integration } \\
\hline $\mathrm{DC}$ & 94 & 179 & 341 & 5.6 & 0.85 & 86 & 82 & 85 & 91 & 25 & 14 & 9 & 49 & 0.81 \\
\hline Los Angeles & 60 & 134 & 182 & 12.8 & 0.89 & 11 & 55 & 59 & 53 & 7 & 44 & 15 & 32 & 0.80 \\
\hline New York & 47 & 232 & 750 & 18.9 & 0.67 & 27 & 34 & 45 & 46 & 16 & 23 & 10 & 49 & 0.81 \\
\hline Miami & 46 & 112 & 168 & 5.6 & 0.86 & 30 & 46 & 25 & 44 & 20 & 42 & 2 & 35 & 0.75 \\
\hline Honolulu & 43 & 52 & 53 & 1.0 & 0.84 & 5 & 10 & 43 & 34 & 2 & 8 & 52 & 19 & 0.78 \\
\hline San Francisco & 39 & 78 & 137 & 4.3 & 0.93 & 16 & 35 & 38 & 38 & 8 & 22 & 24 & 42 & 0.85 \\
\hline Riverside & 26 & 87 & 130 & 4.2 & 0.93 & 17 & 26 & 22 & 25 & 7 & 47 & 6 & 37 & 0.74 \\
\hline Sacramento & 22 & 46 & 83 & 2.1 & 0.86 & 12 & 21 & 21 & 22 & 7 & 20 & 12 & 56 & 0.77 \\
\hline Albuquerque & 19 & 51 & 77 & 0.9 & 0.53 & 0 & 19 & 0 & 19 & 2 & 47 & 2 & 42 & 0.66 \\
\hline Seattle & 17 & 39 & 204 & 3.4 & 0.90 & 11 & 10 & 16 & 17 & 5 & 9 & 12 & 68 & 0.65 \\
\hline \multicolumn{15}{|l|}{ Diverse } \\
\hline Chicago & 5 & 96 & 388 & 9.5 & 0.85 & 4 & 4 & 4 & 5 & 17 & 21 & 6 & 55 & 0.74 \\
\hline Houston & 7 & 88 & 161 & 5.9 & 0.53 & 6 & 7 & 4 & 7 & 17 & 35 & 7 & 40 & 0.80 \\
\hline Atlanta & 6 & 87 & 167 & 5.3 & 0.41 & 6 & 4 & 6 & 6 & 32 & 10 & 5 & 51 & 0.73 \\
\hline Philadelphia & 10 & 73 & 293 & 6.0 & 0.49 & 10 & 5 & 9 & 9 & 20 & 8 & 5 & 65 & 0.64 \\
\hline Dallas & 4 & 72 & 220 & 6.4 & 0.87 & 3 & 4 & 2 & 4 & 15 & 27 & 5 & 50 & 0.76 \\
\hline San Antonio & 14 & 50 & 72 & 2.1 & 0.45 & 9 & 14 & 10 & 14 & 6 & 54 & 2 & 36 & 0.63 \\
\hline Orlando & 16 & 46 & 101 & 2.1 & 0.68 & 15 & 16 & 16 & 16 & 15 & 25 & 4 & 53 & 0.74 \\
\hline Austin & 6 & 40 & 66 & 1.7 & 0.54 & 3 & 6 & 5 & 6 & 7 & 31 & 5 & 55 & 0.69 \\
\hline Richmond & 2 & 39 & 59 & 1.3 & 0.50 & 2 & 2 & 0 & 2 & 29 & 5 & 3 & 60 & 0.63 \\
\hline Phoenix & 2 & 38 & 86 & 4.2 & 0.81 & 0 & 2 & 0 & 2 & 5 & 29 & 3 & 59 & 0.66 \\
\hline
\end{tabular}


Table 3. Descriptive Statistics of the Local Characteristics of Places and Associated MSA by Integration Status (2008-12 ACS 5-year Estimates and 2010 Census)

\begin{tabular}{|c|c|c|}
\hline & $\begin{array}{c}\text { Integrated } \\
(\mathrm{n}=763)\end{array}$ & $\begin{array}{c}\text { Not } \\
\text { integrated } \\
(\mathrm{n}=3,022)\end{array}$ \\
\hline \multicolumn{3}{|l|}{ Place characteristics } \\
\hline Military & 26.3 & 7.8 \\
\hline Public university & 4.8 & 3.6 \\
\hline Public-sector & 15.3 & 7.0 \\
\hline \multicolumn{3}{|l|}{ Mean (sd) } \\
\hline Percent renter-occupied & $38.6(24.9)$ & $36.7(15.9)$ \\
\hline Percent new housing & $30.6(25.1)$ & $26.3(19.1)$ \\
\hline \multicolumn{3}{|l|}{ MSA characteristics } \\
\hline Suburbs (\%) & 99.5 & 91.9 \\
\hline \multicolumn{3}{|l|}{ Size $(\%)$} \\
\hline Large & 68.3 & 51.6 \\
\hline Medium & 24.2 & 31.1 \\
\hline Small & 7.5 & 17.3 \\
\hline \multicolumn{3}{|l|}{ Mean (sd) } \\
\hline Diversity (entropy) & $0.73(0.12)$ & $0.65(0.13)$ \\
\hline Political fragmentation & $0.74(0.16)$ & $0.63(0.17)$ \\
\hline Coastal/border state (\%) & 90.6 & 74.8 \\
\hline
\end{tabular}




\section{Figures}

Figure 1. Graph of Predicted Probabilities of Black-White Integration Generated by Multivariate Logistic Regression.

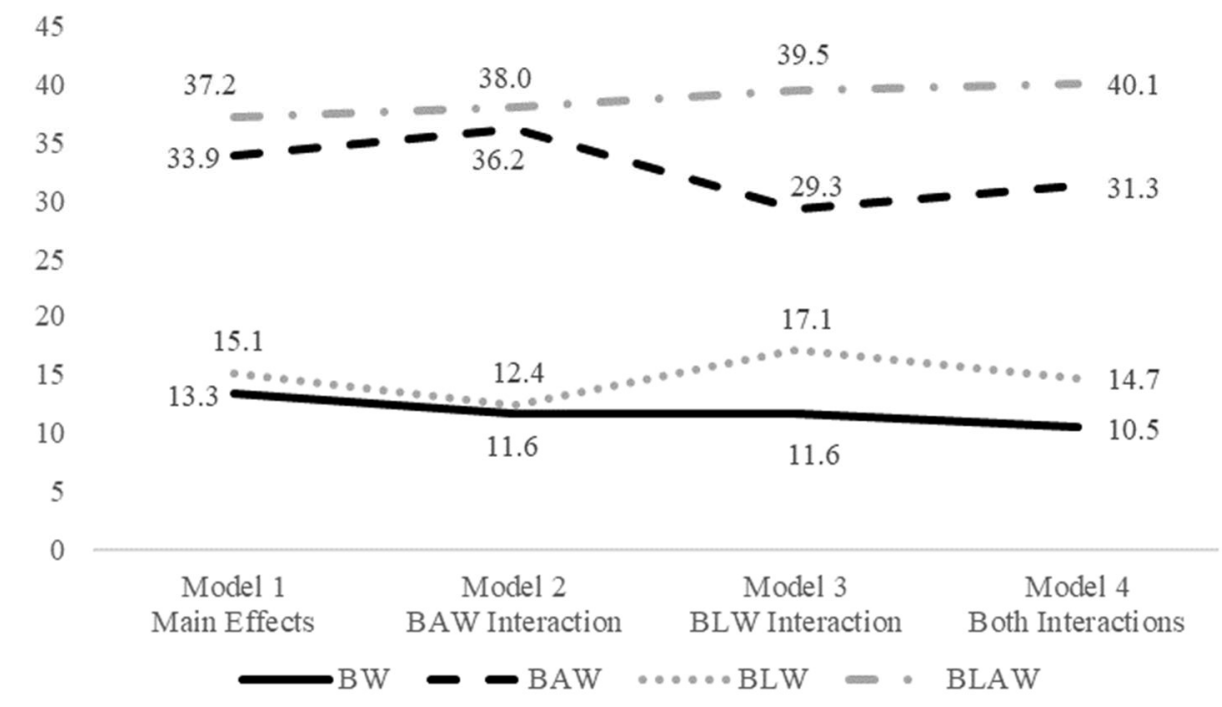

Note: Model 1 includes only the main effects of race and ethnicity; Model 2 includes the blackAsian-white interaction term; Model 3 includes the black-Latinx-white interaction term; and, finally, Model 4 includes both interaction terms. All models control for institutional hubs, land area, nativity, rental units, new housing stock, suburban status, size of MSA, MSA fragmentation, MSA diversity, coastal/southern border state location, and spatial autocorrelation. I generate these probabilities by setting all continuous variables to their mean, for suburbs in a coastal/border state that are not an institutional hub. 
Figure 2. Graph of Odds Ratios and 95\% Confidence Intervals from the Logistic Regression Predicting Integration.
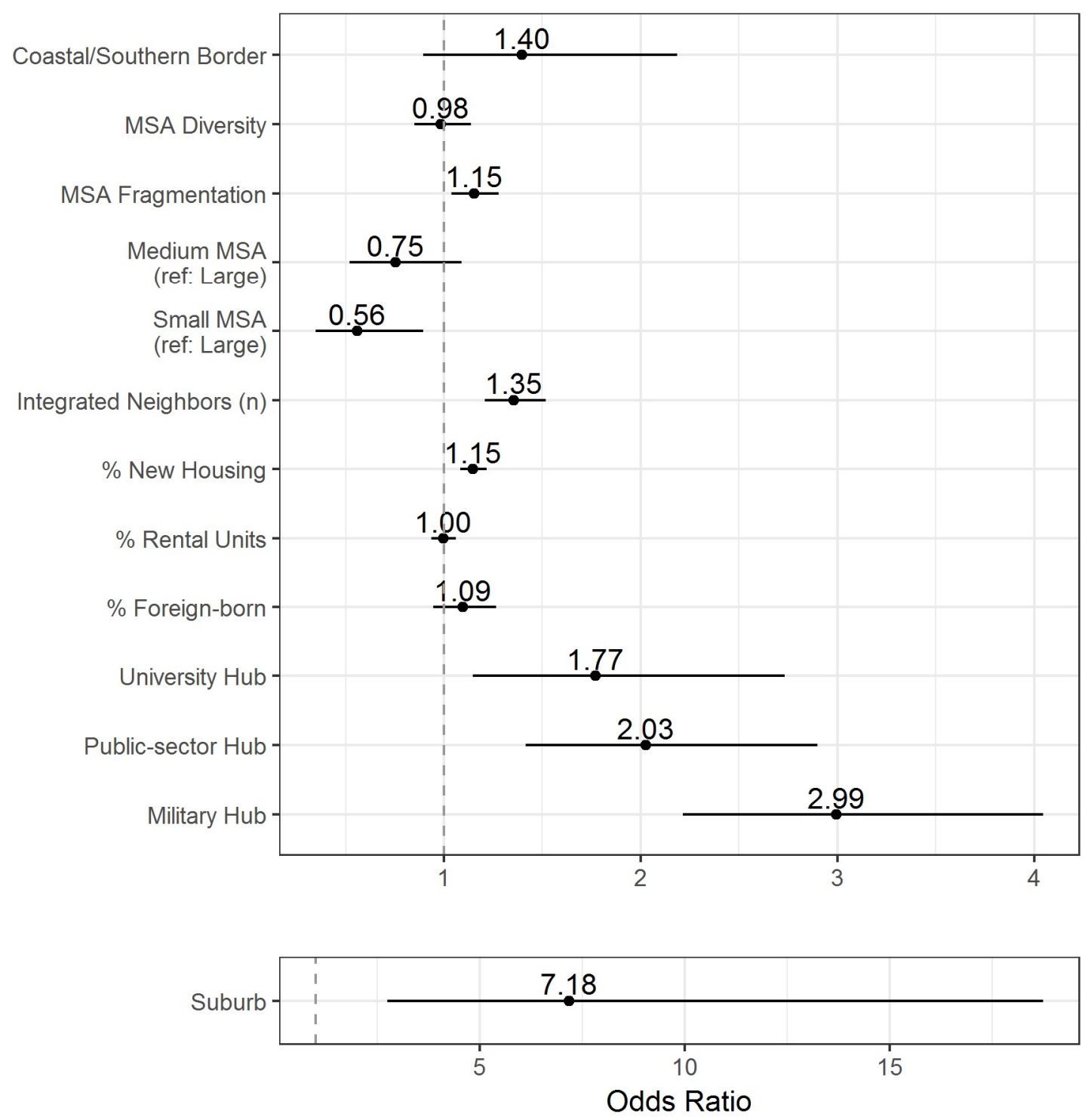

Note: Results correspond to Model 4 in Appendex Table A1 and includes the main effects of the racial and ethnic composition variables as well as the interaction terms for Asian and Latinx buffering. This model further controls for physical land area. For interpretability of effect sizes, I scaled percent and probability variables to 10 percentage-point units. For example, a 10 percentage-point increase in fragmentation associates with an odds ratio of 1.15. 


\section{Appendix A: Additional Results}

Table A1. Logistic Regression Predicting the Odds of Integration, Odds Ratios (95\% CI).

Racial and ethnic

Model 1

Model 2 Model 3

Model 4

composition

( $25 \%$ criterion)

Asian

$3.34(2.50,4.45) \quad 2.49(1.72,3.60) \quad 3.16(2.38,4.19) \quad 2.50(1.70,3.68)$

Black

$0.76(0.60,0.96) \quad 0.51(0.33,0.79) \quad 0.36(0.21,0.62) \quad 0.28(0.15,0.51)$

Latinx

$1.15(0.80,1.67) \quad 1.08(0.75,1.57) \quad 0.64(0.45,0.91) \quad 0.64(0.45,0.90)$

White

BAW interaction

$1.84(1.21,2.80) \quad 1.43(0.90,2.28) \quad 1.13(0.68,1.87) \quad 0.97(0.56,1.68)$

$1.74(1.10,2.75)$

$1.55(0.97,2.49)$

BLW interaction

$2.47(1.44,4.23) 2.30(1.35,3.91)$

Place

characteristics

Institutional hub

Military

$3.11(2.32,4.17) \quad 3.06(2.27,4.12) 3.03(2.25,4.08) \quad 2.99(2.22,4.05)$

University

$1.74(1.13,2.68) \quad 1.72(1.11,2.66) \quad 1.79(1.16,2.75) \quad 1.77(1.15,2.73)$

Public-sector

$2.09(1.47,2.98) \quad 2.07(1.45,2.95) 2.05(1.44,2.93) \quad 2.03(1.42,2.90)$

Percent variables

Foreign-born

$1.12(0.97,1.28) \quad 1.11(0.96,1.27) \quad 1.10(0.95,1.27) \quad 1.09(0.95,1.27)$

Rental units

$0.99(0.93,1.06) \quad 0.99(0.93,1.06) \quad 0.99(0.93,1.06) \quad 1.00(0.93,1.06)$

New housing

$1.15(1.08,1.21) \quad 1.14(1.08,1.21) \quad 1.15(1.09,1.22) \quad 1.15(1.08,1.22)$

Integrated neighbors

(n)

$1.37(1.23,1.53) \quad 1.37(1.22,1.53) \quad 1.36(1.21,1.52) 1.35(1.21,1.52)$

Land area

(ref: 4th quartile)

$1 \mathrm{st}$

$4.15(3.07,5.62) \quad 4.09(3.02,5.54) 4.19(3.11,5.65) \quad 4.15(3.08,5.58)$

2nd

$2.69(2.02,3.60) \quad 2.65(1.98,3.55) 2.66(2.00,3.54) 2.63(1.97,3.50)$

3rd

$1.92(1.44,2.55) \quad 1.90(1.43,2.54) \quad 1.90(1.43,2.54) \quad 1.89(1.42,2.52)$

Metropolitan

characteristics

Suburb

Size (ref: Large)

Medium

$7.16(2.71,18.9) \quad 7.24(2.76,19.0) 7.13(2.71,18.7) \quad 7.18(2.75,18.7)$

Small

$0.76(0.52,1.10) \quad 0.78(0.54,1.12) \quad 0.74(0.51,1.08) \quad 0.75(0.52,1.09)$

Percent variables

Fragmentation $\quad 1.16(1.04,1.28) \quad 1.16(1.04,1.28) \quad 1.15(1.04,1.28) \quad 1.15(1.04,1.28)$

\begin{tabular}{lllllll} 
Diversity & $0.97(0.84,1.12)$ & $0.98(0.85,1.14)$ & $0.97(0.84,1.12)$ & $0.98(0.85,1.14)$ \\
\hline
\end{tabular}

$\begin{array}{llllll}\text { Coastal/border } & 1.38(0.89,2.15) & 1.40(0.90,2.17) & 1.38(0.88,2.15) & 1.40(0.89,2.18)\end{array}$

Note: Model 1 includes only the main effects of racial and ethnic composition. Model 2 includes the black-Asian-white (BAW) buffering interaction term. Model 3 includes the black-Latinxwhite (BLW) buffering term. Lastly, Model 4 includes both buffering terms. Percentage variables were scaled to units of 10 percentage-points for easier interpretation of effect sizes. For 
example, a 10 percentage-point increase in foreign-born residents associates with an odds ratio of 1.12 in Model 1. 
Table A2. Metropolitan Areas with the Largest Number (n) of Institutional Hubs.

\begin{tabular}{lclclc}
\hline MSA & Military & MSA & Public-sector & MSA & University \\
\hline Washington, DC & 58 & Washington, DC & 41 & Washington, DC & 4 \\
Honolulu & 37 & Albuquerque & 15 & Richmond & 4 \\
San Diego & 21 & Honolulu & 9 & Phoenix & 4 \\
Seattle & 14 & Santa Fe & 9 & New York & 4 \\
San Antonio & 12 & Sacramento & 7 & Santa Fe & 3 \\
Virginia Beach & 11 & Philadelphia & 6 & Sacramento & 3 \\
Philadelphia & 9 & Hinesville, GA & 6 & Philadelphia & 3 \\
Dover & 8 & Richmond & 6 & Las Cruces, NM & 3 \\
Baltimore & 8 & Pheonix & 6 & Salisbury, MD & 3 \\
Riverside & 7 & El Centro, CA & 6 & Valdosta, GA & 3 \\
\hline
\end{tabular}




\section{Appendix B: Sensitivity Analyses}

Table B1. Logistic Regression Predicting Integration, Odds Ratios (95\% CI).

\begin{tabular}{|c|c|c|c|c|}
\hline & $\begin{array}{c}\text { Absolute cutoff } \\
70 \% \\
(\mathrm{n}=2,288) \\
\end{array}$ & $\begin{array}{l}\text { Integration by } \mathrm{H} \\
\text { tertile }(\mathrm{H} \leq 0.17) \\
\end{array}$ & $\begin{array}{c}\text { Military } \\
\text { installation }\end{array}$ & $\begin{array}{l}\text { Military hub } \\
(\geq 10 \%)\end{array}$ \\
\hline \multicolumn{5}{|l|}{$\begin{array}{l}\text { Racial and ethnic } \\
\text { composition } \\
\text { ( } 25 \% \text { criterion) }\end{array}$} \\
\hline Asian & $2.16(1.28,3.65)$ & $2.10(1.53,2.87)$ & $2.53(1.72,3.72)$ & $2.50(1.69,3.69)$ \\
\hline Black & $0.24(0.12,0.49)$ & $0.24(0.14,0.40)$ & $0.29(0.16,0.54)$ & $0.29(0.16,0.53)$ \\
\hline Latin $x$ & $0.81(0.42,1.54)$ & $0.81(0.54,1.23)$ & $0.55(0.38,0.80)$ & $0.58(0.41,0.82)$ \\
\hline White & $0.67(0.34,1.35)$ & $0.81(0.48,1.35)$ & $0.88(0.52,1.49)$ & $0.93(0.56,1.55)$ \\
\hline BAW interaction & $1.84(0.99,3.44)$ & $1.89(1.27,2.81)$ & $1.63(1.03,2.56)$ & $1.60(1.02,2.52)$ \\
\hline BLW interaction & $2.32(1.23,4.38)$ & $2.25(1.46,3.46)$ & $2.26(1.27,4.01)$ & $2.22(1.28,3.86)$ \\
\hline \multicolumn{5}{|c|}{ Place } \\
\hline \multicolumn{5}{|l|}{ characteristics } \\
\hline \multicolumn{5}{|l|}{ Institutional hub } \\
\hline Military & $3.30(2.27,4.79)$ & $2.73(2.02,3.69)$ & $35.1(12.7,97.3)$ & $8.06(4.00,16.3)$ \\
\hline University & $1.39(0.78,2.49)$ & $1.89(1.22,2.92)$ & $1.77(1.19,2.64)$ & $1.77(1.18,2.66)$ \\
\hline Public-sector & $2.12(1.26,3.56)$ & $1.89(1.36,2.63)$ & $1.47(0.98,2.20)$ & $1.64(1.14,2.35)$ \\
\hline \multicolumn{5}{|l|}{ Percent variables } \\
\hline Foreign-born & $1.11(0.95,1.30)$ & $1.12(0.99,1.27)$ & $1.09(0.95,1.26)$ & $1.08(0.94,1.25)$ \\
\hline Rental units & $0.98(0.91,1.06)$ & $0.97(0.91,1.03)$ & $0.93(0.88,0.98)$ & $0.96(0.91,1.02)$ \\
\hline New housing & $1.16(1.08,1.25)$ & $1.10(1.05,1.16)$ & $1.15(1.08,1.22)$ & $1.15(1.08,1.21)$ \\
\hline \multicolumn{5}{|l|}{ Integrated } \\
\hline neighbors (n) & $1.40(1.23,1.59)$ & $1.49(1.37,1.61)$ & $1.42(1.27,1.59)$ & $1.39(1.25,1.55)$ \\
\hline \multicolumn{5}{|c|}{$\begin{array}{l}\text { Land area } \\
\text { (ref: 4th quartile) }\end{array}$} \\
\hline $1 \mathrm{st}$ & $4.88(3.25,7.31)$ & $3.03(2.24,4.11)$ & $4.09(3.08,5.43)$ & $4.12(3.11,5.47)$ \\
\hline 2nd & $2.67(1.77,4.03)$ & $2.03(1.59,2.58)$ & $2.50(1.89,3.31)$ & $2.65(2.00,3.51)$ \\
\hline $3 \mathrm{rd}$ & $1.81(1.32,2.47)$ & $1.63(1.29,2.05)$ & $1.81(1.36,2.40)$ & $1.89(1.42,2.53)$ \\
\hline \multicolumn{5}{|l|}{ Metropolitan } \\
\hline Suburb & $7.80(2.70,22.6)$ & $6.46(3.08,13.6)$ & $5.34(2.11,13.5)$ & $7.56(3.13,18.3)$ \\
\hline \multicolumn{5}{|l|}{ Size (ref: Large) } \\
\hline Medium & $0.81(0.51,1.28)$ & $0.72(0.52,1.00)$ & $0.88(0.57,1.36)$ & $0.76(0.51,1.13)$ \\
\hline Small & $0.61(0.34,1.10)$ & $0.53(0.35,0.80)$ & $0.66(0.39,1.11)$ & $0.56(0.34,0.90)$ \\
\hline \multicolumn{5}{|l|}{ Percent variables } \\
\hline Fragmentation & $1.10(0.96,1.26)$ & $1.15(1.05,1.25)$ & $1.14(1.01,1.29)$ & $1.17(1.04,1.31)$ \\
\hline Diversity & $1.01(0.83,1.23)$ & $0.98(0.86,1.12)$ & $1.03(0.88,1.20)$ & $0.97(0.84,1.13)$ \\
\hline Coastal/border & $1.07(0.61,1.85)$ & $1.40(0.97,2.02)$ & $1.57(0.98,2.50)$ & $1.65(1.04,2.61)$ \\
\hline
\end{tabular}


Note: For the $70 \%$ absolute cutoff sensitivity analysis, the first quartile marker for $\mathrm{H}$ remained 0.14 in both 2000 and 2010. Percentage variables were scaled to units of 10 percentage-points for easier interpretation of effect sizes. 